\title{
Exploration on Mechanical Properties and Brittleness Evaluation of Shale Rocks
}

\author{
Zhao Wenjun ${ }^{1}$ \\ ${ }^{1}$ Hunan City University, Yiyang, Hunan, 413000
}

Keywords: shale reservoir rock; mechanical properties; brittleness evaluation

\begin{abstract}
With the development of science and technology and continuous improvement of construction technology, the continuous construction technology of long span in bridge construction has been widely used, which has improved the reliability and safety of the bridge. The main features of construction technology includes the basic construction and structural construction of the upper and lower parts of the bridge. In the process of bridge construction, large-span continuous construction technology is mainly used in the construction of cable-stayed bridges, arch bridges and suspension bridges, and has achieved good results. The key to long-span continuous construction technology is linear control, stress control and stability control.
\end{abstract}

\section{Introduction}

With the rapid development of the market economy in our country, the demand for oil and gas has increased. China is rich in oil and gas resources, while shale is an important oil and gas resource, showing some particularities. In order to ensure the smooth progress of the oil and gas development process, it is necessary to carry out scientific research on shale characteristics during the exploitation to determine the shale permeability and porosity. [1] During the process of oil and gas development, it can be found that the rock fragility of shale reservoirs has an impact on oil and gas quality. Therefore, it is necessary to study the brittleness and mechanical properties of shale reservoirs [2].

\section{The Mechanical Properties of Shale Reservoir Rocks}

\subsection{Test equipment and experimental program}

The rock mechanics characteristics of shale reservoir have a certain impact on oil and gas exploration. In order to ensure the efficiency and quality of mining, it is necessary to study the rock mechanics characteristics of reservoir. In the actual experimental research, experiments of stress and strain, rock pore permeability, X-ray diffraction and acoustic wave measurement were designed so as to grasp the mechanical characteristics of rock in a more comprehensive way and provide references for the formulation of oil and gas exploration programs. The stress-strain test can refer to the research results that have been achieved in foreign countries. For example, the triaxial rock mechanics testing system is used to process the research samples and collect the stress and strain data of reservoir rocks under different conditions. The loading frame of triaxial rock mechanics system can bear a maximum load of 270 tons. The axial displacement and radial displacement sensors used in the test have higher strain sensitivity, accuracy and better temperature resistance. The test object was selected to be 2 inches in length and 1 inch in diameter with a standard specimen of parallel ends. The confining pressure of the rock sample was chosen to simulate the formation stress and the loading rate was set to $0.035 \mathrm{MPa}$ / sec. The pore pressure was modeled as oil Under the condition of the above conditions, the stress-strain curve of deformation or damage of the research object can be obtained by setting the loading rate to be $0.0069 \mathrm{MPa} / \mathrm{sec}$ and the loading rate of the axial pressure to $1 \mathrm{E}-5 \mathrm{~mm} / \mathrm{mm} / \mathrm{sec}$ According to the data in the graph, the mechanical parameters such as Young's modulus, compressive strength, volumetric compressibility, Poisson's ratio, pore elastic coefficient and particle compressibility of rock samples can be calculated.[1] Based on the understanding of mechanical properties of rock samples, it provides a reference for the formulation of reservoir rock oil and gas resource exploration plans, which has 
some practical significance. The core of this study is derived from the Qingshankou Formation of Daqing Oilfield. [2] The gas porosity under confining pressure is $1 \%$ to $16 \%$ and the permeability does not exceed 510-3um2. The mineral composition of the rock samples mainly includes feldspar, quartz, dolomite and calcite, while the clay components are mainly chlorite and illite. By calculating the stress-strain curve, the following data can be obtained [2].

Table 1. Single axial mechanical parameters of shale rock.

\begin{tabular}{|l|c|c|c|c|}
\hline Sample number & density/g $\bullet \mathrm{cm}-3$ & $\begin{array}{r}\text { Young } \\
\text { modulus/GPa }\end{array}$ & Poisson's ratio & $\begin{array}{l}\text { compressive } \\
\text { strength/MPa }\end{array}$ \\
\hline $2-2$ & 2.28 & 15.94 & 0.22 & 15.92 \\
\hline $8-2$ & 2.28 & 17.48 & 0.25 & 17.84 \\
\hline 1 & 2.34 & 14.6 & 0.18 & 14.2 \\
\hline
\end{tabular}

Table 2 data table of triaxial mechanics experiment of mud shale.

\begin{tabular}{|c|c|l|l|c|}
\hline Sample number & density/g • cm-3 & $\begin{array}{l}\text { Young } \\
\text { modulus/GPa }\end{array}$ & Poisson's ratio & $\begin{array}{l}\text { compressive } \\
\text { strength/MPa }\end{array}$ \\
\hline $2-3$ & 2.50 & 37.12 & 0.29 & 333.2 \\
\hline $5-1$ & 2.45 & 60.51 & 0.35 & 347.3 \\
\hline $4-1$ & 2.44 & 47.9 & 0.28 & 319.2 \\
\hline $5-2$ & 2.65 & 22.82 & 0.22 & 245.4 \\
\hline
\end{tabular}

\subsection{Rock mechanics experiment}

In the rock experiment, mainly for rock uniaxial and triaxial mechanics test parameters. Five shales can be selected as uniaxial mechanical test objects. Through analyzing the experimental results, the maximum Young's modulus of the sample is $26.5 \mathrm{GPa}$, the minimum is $14.6 \mathrm{GPa}$, the average Poisson's ratio is 0.22, and the average compressive strength is $94.02 \mathrm{MPa}$. As shown in Table 1. In shale shale triaxial mechanics experiment, the general choice of 16 rocks as the object of study, the experiment process, the need to select the confining pressure and pore pressure rate. The experimental results show that the Young's modulus of the rock specimen is up to $60.51 \mathrm{GPa}$, the minimum is $22.82 \mathrm{GPa}$, the average Poisson's ratio is 0.268 , and the average compressive strength is $303.91 \mathrm{MPa}$. Table 2 shows the experimental data [2].

\subsection{Experimental results analysis}

After analyzing the data of Young's modulus, compressive strength and Poisson's ratio of rock samples, it can be found that the mechanical properties of shale under pressure will be destroyed, and the whole show obvious brittle fracture characteristics, and Changes in rock mechanics properties are influenced by a number of factors. Under these conditions, shale reservoirs show significant heterogeneity. The following experimental conclusions can be drawn from the relevant curves: First, the compressive strength of rock samples will increase with the increase of confining pressure. Compressive strength versus confining pressure shows that in the low confining pressure area, the compressive strength of rock samples is positively correlated with confining pressure, and the growth trend is linear. When the confining pressure increases to a certain value, the growth rate decreases Small, showing a non-linear pattern of growth [3]. With the increase of confining pressure, when a certain value is reached, the compressive strength is basically unchanged, indicating that the rock specimen has a specific compressive limit value. Second, when analyzing the relationship between compressive strength and Young's modulus, the corresponding curves can be drawn from the experimental data. The images show that there is a good correlation between the compressive strength and Young's modulus of the rock samples, showing a positive correlation with each other, indicating that the Young's modulus is the parameter that determines rock mechanics It can be used as an important characteristic parameter to study the mechanical properties of shale. At the same time, taking into account the correlation between rock compressive strength and Young's modulus is good, the Young's modulus can be used to calculate the rock compressive strength, rock 
compressive strength can solve the problem of difficult to solve. Compressive strength is usually calculated using the following expression:

$$
\mathrm{Sc}=\mathrm{C} * \mathrm{E}_{\text {sta }}
$$

Where $\mathrm{C}$ is a constant, and the formation conditions. The experimental results show that the relationship between modal modulus and compressive strength in this area is $S=7.9 \mathrm{E}_{\text {sta }}$, the correlation coefficient between the two is large, which can meet the actual production requirements and ensure the compressive strength of shale reservoir to meet the requirements of oil and gas exploration. Improve the quality of oil and gas exploration [3]. Thirdly, there is also a certain correlation between the volume and strain of rock samples and the Poisson's ratio and the Young's modulus. The experimental results show that the volumetric strain will decrease as the Young's modulus decreases Increase, increase with the increase of Poisson's ratio. Generally speaking, the volumetric strain volume characterizes the volume change rate of mud shale before rupture, which can explain the rock brittleness to some extent. In the study of the relationship between volume of rock volume and Poisson's ratio and Young's modulus, the sample experiment was selected as uniaxial pressure to avoid the phenomenon of different volume changes due to the different confining pressure, so as to ensure the experimental results Fourth, during the experiment, it can be found that the higher the confining pressure, the smaller the number of cracks occurred in the rock specimen and the more the failure mode is shear type. The lower the confining pressure is, the more obvious the phenomenon of rock fracture is. The reason of the crack is mainly of splitting, which has a certain influence on the compressive strength of rock samples. The reason for this phenomenon is that with the increase of confining pressure, the longitudinal extension of the crack will be restrained and the number of cracks will be reduced [4].

However, the research on the anisotropy of shale requires the use of high-precision experimental equipment to record the changes of relevant mechanical parameters of rock samples in different directions and to further understand the anisotropy of rock samples. In this experiment, the parallel samples were chosen for comparison of parameters, and the mechanical properties of shale in one direction were studied. Due to the strong anisotropy of shale, which is related to sedimentary orientation during rock formation, types of rock-forming minerals and formation environment, etc., under the circumstance of anisotropy of rock, drilling and drilling in hydrocarbon exploration and Completion of work caused some impact. For example, during the actual oil and gas exploration, the best drilling angle and dominant drilling direction will be selected. The selection of these parameters is related to the anisotropy of shale, further affecting the wellbore integrity. The same is true for the design of rock fracturing design Have a certain impact. In fact, when evaluating the rock compressive strength, in-situ stress and pore pressure of shale reservoirs, they are respectively corresponding to specific evaluation methods. These methods play an important role in oil and gas exploration and production. In order to ensure the quality of oil and gas exploration, Experiments need to determine the relevant parameters required for the application of each evaluation method, such as Poisson's ratio and Young's modulus will be different with the formation conditions vary, but by selecting the area to be mined shale as a test object, Experimental data can be used to calculate the relevant parameters to provide data support for the formulation of oil and gas exploration programs. However, rock brittleness, which is a mechanical parameter of rock mechanics, has not been appraised by now. Therefore, the evaluation method of shale brittleness will be discussed below, in order to get the rock fragility evaluation method with high precision and to ensure the oil and gas exploration Smooth progress. [4]

\section{The Brittleness Research of Shale Reservoir Rock}

The brittleness character of shale rock is one of the most important parameters to characterize rock mechanics. Relevant scholars define the brittleness of rock as the lack of material plasticity. It is considered that when the cohesion inside the rock is destroyed, the material will have brittle failure. When rocks and cast iron are used as the test object, the property that the material is set to break or exceed the yield strength is called brittleness. Geology and related scholars will be broken 
or damaged immediately before the material is characterized by the brittleness, while the material under the conditions of plastic deformation does not occur also exhibit brittle characteristics. There are many ways to evaluate the brittleness of materials, and some scholars have proposed using the difference of firmness and hardness to evaluate the material brittleness. Some scholars suggest using the difference between the tensile strength and the compressive strength to characterize the material brittleness; some scholars think that strain should be destroyed from the specimen Experiments proceed with stress relief rate characterization of brittleness. Due to the different reference objects, make the material brittleness assessment methods vary. These methods are put forward for practical problems, applicable to the corresponding disciplines, but there is no standard method of material brittleness testing [4].

At present, the elastic parameter method commonly used in the evaluation of rock brittleness is that the larger Young's modulus and the lower the Poisson's ratio, the shale has more brittleness. In actual experiments, the fragility of each part of the rock is expressed by different colors, and compared with the rock's own Poisson's ratio and Young's modulus, the rock brittleness can be further calculated. However, using the elastic parameter method to test shale brittleness, the brittleness characteristics of rocks on different blocks can not be compared due to the difference in Young's modulus minimum and maximum calculation methods. And the uncertainty of Young's modulus and Poisson's ratio in the evaluation of rock brittleness will affect the accuracy of brittleness evaluation. In addition, the calculation of rock brittleness parameters requires the use of $\mathrm{P}$ - and S-wave data, while gas and borehole irregularities and other factors will have an impact on the results of the brittleness assessment. In order to enhance the accuracy of shale embrittlement evaluation, Weatherford Corporation proposed the mineral composition method, a rock brittleness assessment method. Shale components mainly include calcite, quartz and clay, quartz which has strong brittleness, the worst clay [4].

Therefore, the quartz content in rock is usually characterized by its brittle character, and by accounting for the proportion of quartz in the above three minerals, some knowledge of rock fragility can be obtained. This method has the advantages of simple operation, but considering the variety of mineral components in the rock, it is not enough to evaluate the rock fragility accuracy by relying only on the compositional contents of the three types of minerals. In view of the shortcomings of the above two kinds of brittleness evaluation methods and the related definitions of brittleness, we think that the volume change rate of rock failure can be used as the characterization parameter of brittleness size. By studying the relationship between brittleness and Poisson's ratio, Young's modulus, Mineral volume correlation between the proposed shale brittle new method, that is, the combination of mineral composition method and elastic modulus. First, numerical simulation is used to show the variation of rock Poisson's ratio and Young's modulus with the content of mineral components. The results show that when the quartz content and Young's modulus increase and the Poisson's ratio decreases, the brittleness of rock gradually increases. When the content of calcite and the Poisson's ratio increase and the Poisson's ratio decreases, it indicates that the rock Fragility is getting weaker. Therefore, it shows that the rock brittleness is mainly related to the quartz content. Based on this, the rock brittleness evaluation shows some science [4].

\section{Conclusion}

In summary, the sustained economic and social development in our country has enabled oil and gas exploration to be upgraded. Under the current background of the times, the demand for oil and gas in social productive life has obviously expanded. Under such circumstances, China has increased its emphasis on oil and gas exploration. In the actual mining process, the quality of oil and gas in the shale reservoir rock has an important influence on the overall mining effect, and the exploitation is relatively difficult. In order to ensure the good effect of oil and gas exploration, it is necessary to study the rock mechanics characteristics of reservoirs and to further develop a scientific exploration program, which is the key to promote sound development of oil and gas exploration. 


\section{References}

[1] Ban Xiaodong.Mechanical characteristics and brittleness evaluation of shale reservoir rock [J]. Journal of Jiangsu Science and Technology Information, 2017 (22): 40-41

[2] Diao Haiyan. Rock mechanics properties and brittleness evaluation of shale reservoirs [J]. Acta Petrologica Sinica, 2013,29 (9): 344-350

[3] Li Qinghui, Chen Mian, Jin Yan, Hou Bing, Zhang Jiazhen. Rock mechanics properties and brittleness evaluation of shale gas reservoirs [J]. Petroleum Drilling Technology, 2012,40 (4): 17-22

[4] Wang Hongjian, Liu Da'an, Huang Zhichuan, Yuan Guangxiang, Lv Xiaochun, Niu Jingrui, Zhao Zijiang, Shi Xiaoying.Model mechanical properties and brittleness evaluation of layered shales [J]. Journal of Engineering Geology, 2017 (6) 